\title{
A busca pelo constitucionalismo justo e eficaz
}

\author{
The search for fair and effective constitutionalism.
}

\section{Marina Cristina Schmaltz Rocha ${ }^{1}$ \\ Fátima de Paula Ferreira ${ }^{2}$}

\section{Resumo}

0 referido trabalho tem por escopo a apresentação do Neoconstitucionalismo no que tange ao seu aspecto histórico, à sua definição, juntamente com suas matérias relacionadas e por fim, 0 trabalho propõe uma discussão sobre a aplicabilidade emblemática e conturbada do "novo direito". Esse artigo científico objetiva incentivar a construção de uma sociedade baseada na concretização e realização efetiva dos valores constitucionais. Constitui-se como foco principal do artigo científico o resgate da contemporaneidade para impor à prática real do Estado e da sociedade os valores substanciais da civilização.

Palavras Chave: Neoconstitucionalismo; Direitos fundamentais; dignidade da pessoa humana; Efetivação constitucional.

\begin{abstract}
This work is scoped to the presentation of the Neoconstitucionalismo regarding the historical aspect, its definition, along with their related material and finally, the work proposes a discussion about the applicability and troubled flagship of the "new right". This article aims to stimulate the construction of a society based on effective implementation and fulfilment of constitutional values. Constitutes itself as the main focus of the article scientific the rescue of contemporaneity to impose real practice of the State and society the substantial values of civilization.
\end{abstract}

Keywords: Neoconstitucionalism; Fundamental rights; Dignity of the human person; Effective constitucionalism.

\section{Introdução}

Inicialmente, insta ressaltar que a Constituição de um Estado reflete a realidade social na qual a sociedade está inserida. Isso significa dizer que a Constituição de um país regula o comportamento humano através de normas, conforme o contexto social, ou seja,

\footnotetext{
${ }^{1}$ Pontifícia Universidade Católica de Goiás (PUC - GOIÁS).

${ }^{2}$ Pontifícia Universidade Católica de Goiás (PUC - GOIÁS).
} 
de acordo com os valores so ciais seguidos. No entanto, essas normas são insuficientes para a obtenção do idealismo constitucionalista, que é a concretização dos direitos fundamentais e a consolidação do princípio da dignidade humana. Esse é o objeto de estudo do presente artigo científico.

Hodiernamente, temos um Estado envelhecido em suas estruturas, calcado por fragilidades, opressões, injustiças e crueldade, e que precisa ser transformado em um Estado Nação sólido, seguro, justo e solidário.

O Neoconstitucionalismo transcende o viés do puro positivismo, enfocando um papel mais efetivo da Constituição nos Poderes Públicos, na sociedade e na implementação dos direitos sócio econômicos, culturais e dentre outros. Además, constitui um instrumento para garantir a ordem suprema do cidadão.

0 presente trabalho tem como postulado o Direito como um instituto de ativismo social, em evidente e clara busca pela justiça distributiva e pela consolidação dos direitos fundamentais.

0 tema escolhido para compor o artigo científico se justifica pelo fato de que 0 Direito, de um modo geral, hodiernamente, se constitui de um sistema envelhecido em suas estruturas políticas, econômicas e sociais, o que provoca a necessidade da implementação do Neoconstitucionalismo.

Perante a opressão nas relações sociais, de acordo com pesquisas tais como do Conselho Nacional de Justiça (CNJ), do dia 14 de setembro de 2010: mais de 71\% (setenta e um por cento) dos processos recebidos pela justiça brasileira em 2009 não foram solucionados, o que demonstra imenso congestionamento do judiciário brasileiro, e ainda, esses dados permitem sobrelevar a importância do Neoconstitucionalismo na contemporaneidade.

Outra situação que nos dá respaldo pela relevância do Neoconstitucionalismo é a degradação dos sistemas de saúde, educação, habitação, entre outros direitos elencados na Constituição Federal de 1988, o que implica na insurgência do fenômeno Neoconstitucionalista, como fomento à materialização dos direitos fundamentais.

o Brasil tem a maior taxa de abandono escolar no ensino médio dentre Argentina, Chile, Paraguai, Uruguai e Venezuela: $10 \%$. Ou seja, 1 (um) em cada 10 (dez) jovens acabam abandonando a escola nesta etapa, segundo a Síntese de Indicadores Sociais, do Instituto 
Brasileiro de Geografia e Estatística (IBGE) divulgada no dia 17 de setembro de 2010. Essa estatística revela outro fator que incita a utilização do Neoconstitucionalismo como instituto valorativo da normativa constitucional, com a finalidade de realizar veementes os direitos do cidadão na atualidade. ${ }^{3}$

Constitui-se como foco principal deste artigo científico o resgate dos direitos humanos, direitos do homem, das liberdades públicas e predominantemente, dos direitos e liberdades fundamentais para a contemporaneidade com o fito de impor à prática real do Estado e da sociedade os valores substanciais da civilização.

\title{
Aspectos gerais históricos do neoconstitucionalismo
}

O histórico do Neoconstitucionalismo sobre o qual se discorrerá está de acordo e embasado com Luís Roberto Barroso, (2009, p.1/40).

A origem da nova tendência constitucional, ou seja, da nova forma de se interpretar o Direito Constitucional, que se denomina de Neoconstitucionalismo, foi na Europa, no período do pós-guerra (Segunda Guerra M undial), primordialmente na Alemanha e Itália.

Como aduz André Rufino do Vale, (2007), sobre a origem do Neoconstitucionalismo:

\begin{abstract}
Não se trata, portanto, de um movimento, mas de um conjunto de posturas teóricas que adquiriram sentidos comuns ao tentar explicar o direito dos Estados constitucionais, especificadamente aqueles que, a partir do segundo pós-guerra, em momentos históricos de repúdio aos recém-depostos regimes autoritários, adotaram constituições caracterizadas pela forte presença de direitos, princípios e valores e de mecanismos rígidos de fiscalização da constitucionalidade - manejados por um órgão jurisdicional especializado, normalmente o Tribunal Constitucional como as Constituições da Itália (1948), Alemanha (1949) e Espanha (1978), contexto no qual as Constituições de Portugal (1976) e do Brasil (1988) inserem-se perfeitamente.
\end{abstract}

Com 0 advento da Segunda Guerra Mundial, o mundo se dilacerou, porque essa guerra foi um conflito militar global que envolveu a grande maioria das nações, inclusive as grandes potências, deixando milhares de pessoas mortas. Indubitavelmente, foi a guerra mais letal da humanidade.

Com o término da Segunda Guerra M undial, a Europa estava arrasada estrutural, social e economicamente. Cumpre salientar ainda que com o fim da guerra, o mundo tinha

\footnotetext{
${ }^{3}$ WWW.ibge.gov.br, acessado em setembro de 2010.
} 
um novo alinhamento político, econômico e social, a Organização das Nações Unidas (ONU) surgia para estabelecer metas de integração e cooperação entre os países, para evitarem possíveis conflitos futuros.

Pode-se afirmar que o Neoconstitucionalismo surge após a Segunda Guerra Mundial, momento em que a Europa, aniquilada pelos efeitos da guerra, realiza a redefinição da Constituição e seu papel na sociedade contemporânea. Nesse diapasão, as noções de Constitucionalismo e Democracia perfazem uma aliança, modificando a estrutura social, política, econômico financeiras da sociedade moderna.

Insta relembrar que antes de 1945, predominava a supremacia do Poder Legislativo na Europa, entretanto, ao final da década de 40 (quarenta), houve uma evolução, e a partir de então, ocorreu a hegemonia da Constituição, como sendo a fonte primária da ciência jurídica.

O marco inicial da ciência Neoconstitucionalista foi com a Lei Fundamental de Bonn, da Constituição Alemã de 1949, consequentemente com a fundação do Tribunal Constitucional Federal, em 1951, que definiu os direitos civis e os fundamentos jurídicos do país. Logo após, veio a Constituição da Itália de 1947, com a criação da Corte Constitucional em 1956. Essas cúpulas constitucionais da Alemanha e Itália ensejaram a consolidação da ciência do novo Constitucionalismo, devido à vastidão teórica e jurisprudencial feita por essas cortes sobre o novo direito constitucional.

No decorrer da década de 70 (setenta), foi a vez de Portugal e Espanha transcenderem os horizontes do direito constitucional, adicionando valor e estudos à nova tendência do Constitucionalismo.

No Brasil, por sua vez, a Constituição de 1988 foi a grande propulsora da nova vertente do direito constitucional. Pode-se asseverar que com a promulgação da carta Constitucional de 1988, ocorreu a transição de um Estado opressivo, totalitário, ditatorial para um Estado Democrático de Direito, no qual impera a igualdade, a dignidade da pessoa humana, a moral, a ética, a liberdade, o equilíbrio e a valorização humana.

Com a invocação da Constituição de 1988, o direito constitucional no Brasil passou de irrelevante para uma ciência eminente, e de credibilidade, com fundamentos de liberdade, efetivação dos direitos fundamentais e bem estar social. 
No século XX, o paradigma da Constituição brasileira muda, pois passamos de um Estado em que a atuação dos Poderes Públicos, em especial do Poder Legislativo, era o cerne da administração pública, para um Estado em que o Poder Judiciário tem o seu reconhecimento, valor e relevância, além de realizar com afinco o conteúdo da Constituição de 1988.

\section{Neoconstitucionalismo: definições e o surgimento no âmbito social.}

O Neoconstitucionalismo abriga a noção de um novo constitucionalismo, calcado na efetivação dos direitos fundamentais e na concreção do princípio da dignidade da pessoa humana, buscando para tanto a equidade, o equilíbrio, a justiça solidária e fraternal dentro da sociedade.

Hodiernamente, vivemos em um mundo globalizado, travestido de injustiças, barbáries e complexidades. É a partir dessa premissa que nasce a indispensabilidade do Neoconstitucionalismo, como novo modelo de Estado, voltado para dar outra perspectiva às relações jurídicas. Perspectiva essa que se apresenta com a formação de um novo Estado de Direito Constitucional, visando um comportamento ativo e eficiente do Poder Público em prol das necessidades sociais.

O Neoconstitucionalismo demarca uma passagem do Estado de Direito Tradicional, baseado apenas no positivismo normativo, para um Estado no qual o direito se vincula diretamente com a moral e política, colimando o bem estar social dos indivíduos.

0 atual ordenamento jurídico brasileiro precisa ater-se aos valores e princípios constitucionais, de modo que haja respeito e consideração com as pessoas, para que estas possam almejar uma vida plena, harmoniosa e digna. Nisso consiste uma das características do Neoconstitucionalismo.

0 fenômeno Neoconstitucionalista prima pelo Princípio da Supremacia da Constituição, segundo o qual aduz que a interpretação das leis deve ser feita conforme a Constituição, isto é, uma interpretação capaz de ser simétrica com os ideais constitucionalistas, que são a promoção social, política e moral dos indivíduos e da coletividade. 
Ainda no que tange à interpretação das leis, o instituto Neoconstitucionalista defende que se deve alcançar o verdadeiro sentido da norma, ou melhor, o sentido real e social das leis, utilizando o princípio da ponderação e os princípios constitucionais no geral.

Vale salientar que para a aplicação da lei em um caso concreto, o poder jurisdicional não deve estar inerente apenas às normas em abstrato, mas também aos princípios que consagram valores subjetivos, e ainda, complementam e integram o conjunto legislativo.

Corroborando essa idéia, Luis Roberto Barroso $(2007$, p. 9) descreve:

A norma em abstrato não contém integralmente os elementos de sua aplicação. Ao lidar com locuções como ordem pública, interesse social e boa fé, dentre outras, 0 intérprete precisa fazer a valoração de fatores objetivos e subjetivos presentes na realidade fática, de modo a definir o sentido e o alcance da norma.

Impende ressaltar que o Neoconstitucionalismo propõe a prestação social eficaz do Estado para os indivíduos, recordando que os direitos fundamentais possuem aplicação plena, direta e imediata, ou seja, não dependem de qualquer outro dispositivo.

Para confirmar, Amélia Sampaio Rossi (p. 3819/3820) discorre sobre o Neoconstitucionalismo:

É preciso que o Direito seja também um instrumento a ser utilizado para a emancipação do homem, da pessoa humana. 0 fenômeno jurídico não pode se postar apenas a garantir e resguardar as posições dominantes de poder, antes deve servir para transformar a realidade atuando com ferramenta eficaz para a construção de uma sociedade livre, justa e solidária.

Indubitavelmente, o Neoconstitucionalismo vem com o escopo de tornar a Constituição Federal efetiva, ativa e militante na busca incessante pela consolidação dos direitos fundamentais, afastando assim o estereótipo de uma Constituição Federal sem efeito e inerte à realidade.

Alude o Neoconstitucionalismo que a Constituição deve ter o máximo de efetividade. Com efeito, para o cumprimento dessa medida, far-se-á necessário a correspondência entre o que está escrito nas normas, com o que se pratica na realidade. Isso significa que a "nova" Constituição deve proceder à integralização dos anseios da sociedade, transformando-os em axiomas jurídicos. 
Leandro Soares Lomeu (p. 3663) tece alguns comentários sobre 0 Neoconstitucionalismo:

Deve, por fim, ser a Constituição integracionista e universal. A Lei Fundamental deve refletir uma integração ética, moral, espiritual e institucional, tendo em vista o desenvolvimento de funções com fins comuns. Universalista no sentido de conferir uma maior proteção aos direitos fundamentais, cujo fim maior será propiciar a todos uma existência digna.

Os sistemas jurídicos contemporâneos, com a aplicação do Neoconstitucionalismo, seguem o seguinte perfil: "mais princípios que regras; mais ponderação que subsunção; mais Constituição que lei; mais juiz que legislador". (DO VALE, 2003, p. 68).

\section{O neoconstitucionalismo e o jusnaturalismo}

Como é sabido, o positivismo (prevalência da lei), o jusnaturalismo (direito natural, originário) e o realismo jurídico são indissociáveis. Juntos, estes institutos formam uma espécie de tripé, o qual a sociedade está adstrita.

Importante relembrar que o positivismo representa o corpo normativo, o direito objetivo, integrado pelas leis e essencial para a convivência humana harmoniosa. 0 jusnaturalismo, por sua vez, demonstra o direito natural e subjetivo, com um conjunto de primeiros princípios morais, que são imutáveis, previstos ou não no ordenamento jurídico.

Perfazendo uma relação entre os três institutos expostos acima, se obtém que 0 realismo jurídico, isto é, as relações jurídicas societárias, devem ser pautadas pelo positivismo e pelo jusnaturalismo, pois ambos se complementam, se equilibram, realizando uma ponderação de valores.

Outrossim, preceitua M aria Helena Diniz (2006, p. 43):

A ciência do Direito, no jusnaturalismo moderno, que, apesar de não estar preso a nenhuma fonte positiva do direito, Ihe deu a qualidade de sistema, que se constrói a partir de premissas cuja validade repousa na sua generalidade racional, passa a ser um construído sistemático da razão e um instrumento de crítica da realidade. A concepção jusnaturalista de tipo subjetivo ou formal trouxe duas contribuições de grande valia: o método sistemático conforme o rigor lógico da dedução e o sentido crítico avaliativo do direito posto em nome de padrões éticos contidos nos princípios reconhecidos pela razão. 
Mediante tal entendimento, percebe-se que o Constitucionalismo Contemporâneo está concatenado com 0 ideal jusnaturalista, devido ao fato de que aquele postulado reporta-se por atribuir à ciência jurídica a efetivação da Constituição, embasada na realidade da população, através da valoração ética que nasce da sociedade e a predomina.

\section{Neoconstitucionalismo e a efetividade da constituição}

Pode-se afirmar que no âmbito geral das leis, estas possuem, primeiramente, 0 plano da existência, isto é, a presença de agentes jurídicos integrantes na relação que envolve a lei, e a presença de um objeto jurídico, sendo denominado como o bem jurídico tutelado.

Em seguida, tem-se o plano da validade, significando indagar se uma norma preenche os requisitos de validade (competência, pressupostos processuais, etc).

Por derradeiro, uma norma jurídica deve ter plena eficácia, ou seja, além do plano da existência e validade, deve ser efetivada no caso concreto de tal maneira que cumpra a sua função primordial e originária. Portanto, de acordo com Luis Roberto Barroso (2009, p. 83): "a efetividade das normas depende, em primeiro lugar, da sua eficácia jurídica, da aptidão formal para incidir e reger as situações da vida, operando os efeitos que lhe são próprios".

Desta feita, no campo Neoconstitucionalista, a efetividade das normas constitucionais se faz imperiosa, com o fito de tornar a Constituição realizável e exequível, afastando dela os vestígios arraigados da inércia, da ineficácia e da demagogia, propiciando assim a solidificação dos direitos fundamentais e do princípio da dignidade humana.

Neoconstitucionalismo, os direitos humanos e os direitos fundamentais

Primeiramente, cumpre ressaltar que os Direitos Humanos é um ramo da ciência jurídica em eminência, devido às inúmeras violações ocorridas hodiernamente contra o princípio da dignidade da pessoa humana.

Os Direitos Humanos primam pelo bem estar da pessoa, pela realização eficaz de todos os direitos a ela adstritos, pela superação das desigualdades sociais, sendo assim, as 
assertivas dos Direitos Humanos estão evidentemente em aliança com o propósito do Neoconstitucionalismo, assim como, com os valores dos direitos fundamentais.

Vale frisar que é dever do Estado, da sociedade, e de todos os indivíduos da nação, o respeito e a busca incessante pelos princípios dos Direitos Humanos, com a finalidade de se alcançar a emancipação social dos indivíduos, submetendo-se também às referências do Neoconstitucionalismo.

0 artigo 25 da Declaração Universal dos Direitos Humanos assegura:

Todo ser humano tem direito a um padrão de vida capaz de assegurar-Ihe, e a sua família, saúde e bem estar, inclusive alimentação, vestuário, habitação, cuidados médicos e os serviços sociais indispensáveis, e direito à segurança em caso de desemprego, doença, invalidez, viuvez, velhice ou outros casos de perda dos meios de subsistência em circunstâncias fora de seu controle.

0 artigo supracitado relaciona-se com a ideia do "mínimo vital" explanado anteriormente, pois ambos os institutos prezam pela existência do ser humano com o mínimo de dignidade, honra e harmonia.

Afirma José Ricardo Cunha e Nadine Borges, (2009, p. 25), que "a não garantia dos direitos humanos historicamente consagrados e a inexistência ou existência ineficaz de um sistema de proteção dos direitos humanos fere de morte qualquer pretensão político jurídica de constituição do Estado de Direito".

Enfim, mediante os problemas sociais, as crises econômicas, financeiras, políticos sociais e dentre tantas outras, o Estado Democrático de Direito deve assentar-se no sentido de consolidar os direitos fundamentais elencados na Constituição de 1988, assim como enaltecer o viés dos Direitos Humanos, possibilitando um Estado justo socialmente, e igual para todos os nele presentes. Os direitos humanos e os direitos fundamentais compõem uma união indissociável, sendo que, estes dois institutos não caminham sozinhos.

Os direitos fundamentais inseridos na sistemática neoconstitucionalista

A Constituição de um Estado se faz presente para poder limitar o poder estatal, através da garantia dos direitos fundamentais. Os institutos dos direitos fundamentais tutelam as liberdades individuais, de tal sorte que também fazem um controle das ações 
estatais, exercendo um papel de fiscalizador do Poder Estatal, para que este não atue arbitrariamente.

A ideia de justiça, atualmente, é indissociável da assertiva da efetivação dos direitos fundamentais, como meio para se consolidar o verdadeiro Estado Democrático de Direito, sustentáculo do Neoconstitucionalismo. Em verdade, os direitos fundamentais funcionam como elementos materiais principais de todo o ordenamento jurídico.

Os direitos elencados nos arts. 5 ao 17 representam meios de atuação dos povos de uma nação em busca da eficácia do princípio da dignidade da pessoa humana.

Por derradeiro, os direitos fundamentais, os direitos humanos, o Estado Democrático de Direito e o Neoconstitucionalismo são interdependentes e recíprocos, haja vista que a existência de apenas um deles, pressupõe a de todos.

\section{A inércia na aplicação do neoconstitucionalismo no ordenamento jurídico brasileiro}

Atualmente, com a globalização, em suas vertentes maléficas e impositivas, a sociedade sobrevive continuamente a um momento de ceticismo, angústia, indignidade e violação de direitos, que geram um sentimento de insegurança e temor. Para coibir tal insegurança, os postulados Neoconstitucionalistas (pós-constitucionalista) devem ser ovacionados e postos em prática, para se perfazer uma sociedade justa, segura e progressista.

Para demonstrar a obsolescência do nosso sistema jurídico e o não exercício integral dos direitos fundamentais de acordo com os ditames constitucionalistas e pósconstitucionalistas, principia-se por um aspecto histórico brasileiro, o qual se pode afirmar que o Brasil praticamente não foi povoado por povos insurgentes, inconformados e emancipados politicamente, razão pela qual os brasileiros, lamentavelmente, não possuem o sentimento de nação dentro de seus interiores mais íntimos.

No Brasil houve constituições sem a participação do povo, isto é, não houve uma luta política e social por direitos e garantias, o que acarretou em um déficit na formação política da sociedade, que se tornou inerte com relação à ineficácia da consolidação dos direitos constitucionais. 
Já dizia Lima Barreto, escritor e crítico: "O Brasil não tem povo, tem público" 4. Assim, denota-se que uma das justificativas para a inércia do Neoconstitucionalismo no Brasil decorre de sua origem histórica, que não contribuiu para a feitura de um sentimento constitucionalista.

Outro ponto essencial a ser discutido é referente à esmagadora quantidade de leis no ordenamento jurídico brasileiro que não possuem utilidade quando não logram efetivação no campo jurídico. Nota-se que, a edição de medidas legislativas é cada vez mais frequente, não obstante a eficácia dessas leis serem reduzidas.

Com efeito, deve-se objetivar ao invés da criação constante de leis, a efetivação das que já figuram no plano da existência, frisando assim, um funcionamento prático, efetivo, econômico, célere, simples e adequado do sistema jurídico brasileiro, sem a promulgação demasiada de instrumentos normativos.

Hodiernamente, ainda há resquícios na sociedade do Regime Ditatorial de 1964, tais como, a falta de liberdade política, científica e de expressão, que, apesar de estarem guarnecidas pela nossa Constituição Federal de 1988, ainda sofrem restrições por interesses políticos e econômicos da classe dominante.

Outro exemplo de reflexos do Regime Ditatorial na sociedade é a arbitrariedade do Poder Público, que mitiga a ação e reação da sociedade, e de outras entidades públicas que possuem menos poder, fazendo com que os interesses do Poder Público de maior influência predominem sobre os interesses coletivos e difusos.

0 período da Ditadura provocou arbitrariedade, violação de direitos e princípios constitucionais, que culminaram na proibição de manifestações e revoltas populares, que, consequentemente, instauraram nas mentes de hoje o costume da inatividade, do conformismo e da acomodação, antagônicos às desídias Neoconstitucionalistas, que sugerem a vivacidade das participações sociais na política do país.

Salienta lembrar que o aspecto econômico é outro fator contributivo para a inércia do Poder Judiciário em efetivar os preceitos Neoconstitucionalistas, devido à resistência do setor economicamente dominante da sociedade em progredir em favor de interesses públicos e não meramente privados, como o desejado por ele. 0 poder econômico dominante da sociedade impõe os seus imperativos e com eles tenta dominar a política

\footnotetext{
${ }^{4}$ Retirados do site WWW.releituras. com.br, acessado dia 01/04/2011.
} 
societária, fazendo prevalecer seus interesses e privilégios, o que gera a elevação de uma classe social em detrimento de outra, esta que se redunda na miséria, no escracho e abandono social.

A ausência da prática Neoconstitucionalista no ordenamento jurídico brasileiro deve-se também ao exercício do puro positivismo, ou seja, o culto exacerbado ao legalismo, que fulmina no anacronismo das leis, esquecendo os valores da realidade social. Dessa maneira, discorre Manuel Garcia Pelayo, (Derecho constitucional comparado, 1967, p. 20): “Resulta assentado, desse modo, com razoável consenso doutrinário, que o Direito Constitucional, mesmo em sua dimensão positiva, expressa a síntese da tensão entre a norma e a realidade com a qual se defronta".

A defesa de um Estado Constitucional predominantemente positivista vai contra 0 ideário Neoconstitucionalista, pois a nova tendência constitucional enseja a valoração principiológica, peculiar a cada caso concreto analisado, suscitando a valoração dos princípios morais e éticos.

\section{A inefetividade do neoconstitucionalismo no caso concreto no Brasil}

Destaca-se alguns casos ocorridos no seio da sociedade brasileira que denunciam a carência Neoconstitucionalista. Cumpre advertir que esses exemplos não são exaustivos, mas sim exemplificativos, dentre tantas outras violações e deturpações ao novo constitucionalismo, este nascido com a assertiva de se alcançar a plena efetivação Constitucional nos moldes da sociedade brasileira.

O primeiro caso foi retirado da fonte do Conselho Nacional de Justiça (CNJ) no dia 14 de setembro de 2010 , que pontuou que mais de $71 \%$ (setenta e um por cento) dos processos recebidos pela justiça brasileira em 2009 não foram solucionados, o que demonstra imenso congestionamento do judiciário brasileiro. Essa situação desrespeitou 0 art. 5, inciso LXXVIII: "A todos, no âmbito judicial e administrativo, são assegurados a razoável duração do processo e os meios que garantam a celeridade de sua tramitação".

A jurisdição tem o fim de satisfazer aos anseios dos cidadãos e da sociedade no geral, consonante a isso, o Estado deve proporcionar medidas efetivas para solucionar as lides nos casos concretos. Isso implica na celeridade na tramitação processual, com a meta 
de suprir as necessidades populares de forma otimista e rápida, sem demais protelações que obstam ao andamento eficaz do processo.

A razoável duração do processo se encontra prevista igualmente na Convenção Americana sobre Direitos Humanos (Pacto de São José da Costa Rica).

Perante tal informação, originária do Conselho Nacional de Justiça, está nítida na organização judiciária brasileira os entraves burocráticos para a prestação jurisdicional eficaz. O Neoconstitucionalismo reza, por sua vez, pela satisfatória prestação jurisdicional, isso significa que a nova ciência constitucional afere que os trâmites processuais devem ser econômicos, céleres e simples, visando sempre o bem tutelado em um tempo adequado e razoável.

Vale assentar que, de acordo com a Constituição Federal de 1988, o Estado Brasileiro tem o dever de prover educação para todos, visando o pleno desenvolvimento da pessoa, seu preparo para o exercício da cidadania e sua qualificação para o trabalho, como alude 0 art. 205 da Constituição Federal.

Ainda, nos artigos 206 a 214 estão dispostas normas sobre a Educação no Brasil, que conduzem à erradicação do analfabetismo, universalização do atendimento escolar, melhoria da qualidade do ensino, formação para o trabalho, promoção humanística, cientifica e tecnológica do país (artigo 214 da Constituição Federal). Todos esses objetivos constitucionais devem ter fins colimados pelo Estado e pela sociedade, que atuaram em conjunto para a plena difusão da Educação de qualidade no país.

Lamentavelmente, a educação no Brasil nunca se configurou como política pública de prioridade, quando deveria o ser. São diários os descasos com a educação: carência de uma gestão educacional eficiente, falta de verba destinada exclusivamente à educação, falta de professores qualificados e dentre outros gravames relacionados à educação brasileira.

Infortunadamente, a fragilidade e vulnerabilidade da Democracia assolam o nosso país, exemplo disso foi um fato ocorrido no Superior Tribunal Militar (STM) relatado na Folha de S. Paulo, por Jorge Zaverucha e Glaucio Soares, no dia 24 de novembro de 2010:

Ocasião em que o presidente do Superior Tribunal Militar (STM), Carlos Alberto Soares, lacrou, em março de 2010, um processo de teor público. Tentou justificar o injustificável alegando que os papéis eram de "difícil manuseio" e que haveria uma possível implicação para a eleição presidencial. 
Tal entrevero ocorrido representa uma afronta aos direitos constitucionais, essencialmente no que tange ao direito à publicidade dos atos processuais, consoante 0 artigo 93, inciso IX, da Constituição Federal, e ainda ao direito à informação.

A Constituição Federal, em suas novas buscas e exigências, enobrece 0 interesse público à informação, editado pela Emenda Constitucional n. 45/2004. Assim, o pósConstitucionalismo fustiga a concreção da publicidade dos atos processuais, de modo a promover a divulgação desses como forma de estabelecer a Democracia, a transparência, a imparcialidade, e, sobretudo, a confiança e lealdade do Poder Judiciário.

Por fim, o comportamento do Poder Judiciário, subjacente aos seus agentes políticos, deve ser pautado pela publicidade e transparência, sem a invocação de outros direitos fundamentais para fraudar a publicidade dos atos processuais.

\section{Formas gerais de aplicação do neoconstitucionalismo}

Sob a égide Neoconstitucionalista, a fortaleza jurídica brasileira necessita de instrumentos, aparelhos e meios para obter a satisfação plena da Constituição Federal.

Pugna-se, inicialmente, por agentes de conduta decorosa e ilibada, em outras palavras, exigem-se pessoas de boa fé e retas, que se empenhem com lealdade e honra perante a Carta Mãe, realizando os postulados Neoconstitucionalistas. Además, esses membros públicos devem aprimorar sua qualidade técnica e atualização.

Impende alertar que não surte efeito um Estado que possua meios eficazes e seguros de aplicação da Constituição Federal, porém com operadores ou agentes de pouca qualidade e pouco interesse político e social, que não influam na concretização da Constituição Federal, ao contrário, se tornam alienados às demandas constitucionais.

Seguindo a lógica Neoconstitucionalista, para o seu desenvolvimento progressista, é imprescindível a presença de órgãos eminentemente compenetrados com o "compromisso constitucional e pós-constitucional", dispostos a exercerem sua função com altivez e competência, como traz a Carta Máxima do ordenamento jurídico brasileiro.

Insta relembrar que o comportamento dos órgãos não deve se pautar por ilicitudes, fraudes ou desvios na condução dos procedimentos, pois esses atos provocam a usurpação e o retrocesso do movimento Neoconstitucionalista, que precisa da atuação eficiente e ativa dos órgãos, bem como dos agentes supracitados. 
Idealizando um entrelaçamento entre as atuações dos órgãos e agentes públicos, é escorreito afirmar que ambos necessitam atuar em harmonia e progressão, isto é, é indispensável a realização de um trabalho conjunto com o fito de atender a todas as demandas judiciais possíveis, como corolário do Princípio do Acesso à Justiça e da Inafastabilidade do Poder Judiciário, artigo quinto, inciso XXXV, da Constituição Federal.

Neste diploma, para elevar à concretização plena da Constituição Federal, far-se-á imperioso que a capacidade atuante dos órgãos e agentes públicos seja feita de maneira otimista, utilizando-se de recursos aptos a produzirem efeitos benéficos ao sistema jurídico e à sociedade. Esses recursos que serão utilizados poderão ser obtidos de várias formas, dentre elas, pela elaboração de planos de metas, pela produção de acordos e projetos, pelo uso de estratégias e logística, pelas parcerias com outras entidades, pelas políticas públicas e etc.

Por certo, insta pontuar que outro meio para efetivar a Constituição é compatibilizá-la com a realidade social, ou seja, fazer com que as normas constitucionais se amoldem à realidade política social. Neste mesmo viés, é pertinente ratificar que a jurisdição deve, imperiosamente, aplicar a Constituição, respeitando todos os seus princípios.

Ainda, pelo Princípio da Máxima Efetividade da Constituição pode-se aplicar o Neoconstitucionalismo, pois este princípio afere que deve ser dado à norma constitucional o sentido que maior Ihe dê eficácia. Assim, ao se interpretar a norma constitucional, sem importar quem seja, deve-se ter a cautela de aplicar o sentido que maior alcance o objetivo da norma constitucional.

No que se refere à celeridade do Poder Judiciário, já estão sendo utilizadas as tecnologias de inovações: audiências com videoconferência e a digitalização dos processos, o que representam grande solução quanto à morosidade do Judiciário. Essas tecnologias que aceleram os trabalhos do Judiciário devem ser intensificadas e melhores desenvolvidas para perfazer o ideal da razoável duração do processo.

Por ultimato, impende frisar que toda norma constitucional possui efeitos jurídicos, isso significa que, todo preceito constitucional possui alguma eficácia, essa, que por sua vez, varia, porém é eficaz, devendo ser cumprida, obedecida e respeitada pelo Estado e pela sociedade. 
Impinge sobrelevar que, as normas constitucionais possuem suficiência normativa aptas a produzirem todos os seus efeitos, independente de interferência do legislador.

$\mathrm{Na}$ realidade, toda regra constitucional possui um mínimo de eficácia, esta, que poderá ser diferenciada de acordo com o grau de aplicabilidade e eficácia a ela dada, não obstante nunca ter caráter excludente.

Garantias para o direito de acordo com George Jellinek e Almagro Nosete

Segundo Georg Jellinek (Teoria general del Estado, 1981, p. 591) e José Almagro Nosete ( Constitución y proceso, 1984, p. 13-15), "existem três ordens de garantias para 0 Direito: sociais, políticas e jurídicas".

Primeiramente, as garantias sociais consistem na prestação social do Estado para com os indivíduos do país, subjacente às necessidades vitais essenciais do ser humano.

As garantias políticas, por sua vez, consubstanciam-se na organização do Estado, referindo-se aos seus poderes: Legislativo, Judiciário e Executivo, ao equilíbrio e harmonia destes. É certo dizer que as garantias políticas perpassam a ideia da independência e harmonia entre os três poderes.

Finalizando, resta versar sobre as garantias jurídicas, estas que correspondem à prestação jurisdicional do Estado através da instrumentalização do direito material. Essas garantias visam amparar a tutela de direitos lesados ou ameaçados, permitindo a atuação do Poder Judiciário, na sua função precípua.

À guisa de conclusão, cumulando estas três ordens, exsurge a plenitude da Constituição Federal, que assim, logra alcançar os seus princípios primordiais, quais são: 0 amparo social à população; 0 exercício adequado e balanceado dos três poderes; e o serviço e dedicação integral do Judiciário à sociedade.

Aplicação imediata das normas definidoras dos direitos e garantias fundamentais

Como aduz 0 artigo 5, parágrafo primeiro da Constituição Federal, "as normas definidoras dos direitos e garantias fundamentais têm aplicação imediata". Partindo desta premissa, os direitos e garantias fundamentais devem ser aplicados diretamente e imediatamente, independentes de regulamentação posterior ou ulterior. 
Desta feita, os direitos fundamentais são direitos de ordem material, que estão regulamentados na Constituição Federal, assim como, as garantias estão expressas na Constituição Federal para instrumentalizar estes direitos fundamentais, de natureza material.

Nesse sentido, Jorge Miranda apud Alexandre de Moraes, (2004, p. 64), reporta: “(...) os direitos representam só por si certos bens, as garantias destinam-se a assegurar a fruição desses bens (...)".

Deveras, o "novo" Constitucionalismo, como atual instituto máximo de consolidação dos direitos fundamentais, deve procurar instituir e realizar prontamente, através do Estado e da sociedade, todos os direitos fundamentais, fazendo com que estes gozem de eficácia direta e imediata, como obriga a Lei Máxima.

A aplicação imediata e direta dos direitos fundamentais deve ser feita através de Leis, atuando para isso, o Poder Legislativo, também deve ser feita através dos atos administrativos do Poder Executivo, ou então, através dos procedimentos judiciais produzidos pelo Poder Judiciário. Com efeito, tem-se a participação dos três poderes para a efetivação Neoconstitucionalista.

Portanto, com a colaboração e cooperação dos três Poderes e de seus respectivos agentes, perfazendo comportamentos convenientes e em concordância com as acepções constitucionais, o Neoconstitucionalismo será consagrado.

Atuações do ministério público na efetivação do neoconstitucionalismo

O Ministério Público é instituição permanente, essencial à função jurisdicional do Estado, incumbindo-Ihe a defesa da ordem jurídica, do regime democrático e dos interesses sociais e individuais indisponíveis (artigo 127, Constituição Federal).

É sabido que o Ministério Público, autônomo e independente, atua na defesa da sociedade e dos cidadãos. Ele possui atuação tanto no campo penal (titular da ação penal pública) quanto no campo cível e administrativo, como fiscal da legalidade e probidade administrativa. Además, o Parquet é essencial para a garantia da democracia e da liberdade.

Tomando como amostra, especificadamente, o Ministério Público do Estado de Goiás (M PGO), artigo 127 da Constituição Federal, este possui a missão de "defender a ordem jurídica, o regime democrático e os interesses sociais e individuais indisponíveis a fim 
de garantir a cidadania plena e o desenvolvimento sustentável". Ainda, tem-se a sua visão de "ser reconhecida como uma instituição autônoma, independente, proativa e eficaz, transformadora da realidade social, acessível ao cidadão, promotora dos direitos fundamentais e dos interesses sociais para as atuais e futuras gerações". "Os princípios que nortearão o Ministério Público do Estado de Goiás (MPGO) apresentam como ideal uma atuação uníssona com honestidade e compromisso, motivada por coragem, realizada com dedicação e pautada no conhecimento" ${ }^{5}$

Nesse parâmetro, percebe-se a forma como o M inistério Público do Estado de Goiás (M PGO) atua para a realização da democracia plena, perante os paradigmas constitucionais e Neoconstitucionais.

Concluindo-se, o M inistério Público, instituição presente na União e nos Estados da nossa República Federativa Brasileira, assim como outras entidades públicas, tem função relevante na garantia do Neoconstitucionalismo, haja vista que atua em benefício dos interesses ou direitos coletivos e difusos, e direitos individuais homogêneos.

Neste particular, o Ministério Público do Estado de Goiás (MPGO) e os demais Ministérios Públicos dos outros Estados traçam diretrizes e políticas institucionais para a defesa da ordem jurídica e do regime democrático de direito, no que tange à preservação do meio ambiente, à redução dos índices de criminalidade, à lisura do Poder Público, à efetivação dos direitos do consumidor, à realização plena dos direitos dos cidadãos, à proteção das crianças, dos adolescentes, dos idosos, e dos portadores de necessidade especiais, entre tantas outras metas deste Órgão Ministerial para efetivar os valores e interesses sociais e políticos da Constituição Federal.

Garantias constitucionais como meio de instrumentalizar o neoconstitucionalismo

A utilização dos remédios constitucionais também constitui solução prática eficaz para a realização dos direitos fundamentais imbuídos na Constituição Federal.

No bojo da Lei Maior, estão previstos: 0 direito de petição, o direito de certidão, 0 habeas corpus, o mandado de segurança, o mandado de injunção, o habeas data e a ação popular.

Relata Uadi Lammêgo Bulos, (2010, p. 356):

\footnotetext{
${ }^{5}$ www.mp.go.gov.br - 01/04/2011.
} 
Tais instrumentos também são chamados de remédios constitucionais (no sentido de que corrigem atos viciados, impugnando-os, se for o caso, de sorte a restaurar a saúde da liberdade pública lesionada ou ameaçada de lesão), garantias constitucionais (com base na ideia de que visam assegurar o gozo de direitos violados ou em vias de violação, limitando os atos públicos e privados), ações constitucionais (enquanto meios de provocar a atuação do Poder Judiciário) ou, ainda, writs constitucionais (na acepção de que consagram ordens a serem cumpridas pelos Poderes Públicos).

Doravante, passa-se a fazer uma breve síntese de cada garantia constitucional com o intuito de apresentar sua aplicabilidade no Neoconstitucionalismo.

De início, o Direito de Petição, que representa garantia a todos, independente de pagamento de taxas, é o direito de peticionar aos Poderes Públicos: Executivo, Legislativo ou Judiciário, para defender direitos, ou ir contra ilegalidade ou abuso de poder, artigo 5, inciso XXXIV, "a", Constituição Federal. Este remédio constitucional tem por escopo o direito dos indivíduos de "falar" junto aos órgãos públicos, além de expor as irregularidades destes.

Em seguida, discorre-se sobre o direito de obtenção de certidão pública em repartições públicas, para a defesa de direitos e esclarecimento de situações de interesse pessoal, independente do pagamento de taxas, artigo 5, inciso XXXIV, "b", Constituição Federal.

No que se refere ao Habeas Corpus, este é o instrumento processual constitucional, isento de custas, posto à disposição de qualquer pessoa física ameaçada de sofrer violência ou coação em sua liberdade de locomoção, por ilegalidade ou abuso de poder, artigo 5, inciso LXVIII, da Constituição Federal. A finalidade deste remédio constitucional é cessar ou evitar a violência ou coação à liberdade de locomoção ou ambulatorial.

O Mandado de Segurança, por sua vez, visa proteger direito líquido e certo, não amparado por habeas corpus ou habeas data, quando o responsável pela ilegalidade ou abuso de poder for autoridade pública ou agente de pessoa jurídica no exercício de atribuições do Poder Público, artigo 5, inciso LXIX, Constituição Federal. 0 objetivo desta medida é dar força ativa ao Poder Judiciário para combater a ilegalidade ou abuso de poder cometido por autoridades pública ou agente de pessoa jurídica, no exercício de suas atribuições.

$\mathrm{Na}$ outra face das garantias constitucionais está o Mandado de Injunção, usado sempre que a falta de norma regulamentadora torne inviável o exercício dos direitos e 
liberdades constitucionais e das prerrogativas inerentes à nacionalidade, à soberania e à cidadania, artigo 5, inciso LXXI, Constituição Federal. Esta ação constitucional tem o fito de tornar a norma constitucional imediatamente aplicável, produzindo efeitos quer seja no âmbito individual, quer seja no âmbito coletivo. Afirma-se ainda que o Mandado de Injunção serve para preencher as omissões constitucionais, o que abomina a inefetividade da Constituição Federal, condição proeminente do Neoconstitucionalismo.

Seguindo, se estabelece o Habeas Data, procedimento instrumental posto à pessoas físicas e jurídicas, brasileiras ou estrangeiras, para que requeiram ao Poder Judiciário a exibição ou a retificação de dados constantes em registros públicos ou privados, artigo 5, inciso LXXII, Constituição Federal. Possui o foco de conhecer informações relacionadas à pessoa do impetrante, ou até mesmo corrigi-las.

Por derradeiro, consta a Ação Popular, colocada ao alvitre de qualquer cidadão, desde que esteja no pleno exercício de seus direitos políticos, para invalidar atos ou contratos administrativos ilegais ou lesivos ao patrimônio público, à moralidade administrativa, ao meio ambiente e ao patrimônio histórico e cultural da União, Estados, Distrito Federal e Municípios, artigo 5, inciso LXXIII, Constituição Federal. Esta ação processual tem por finalidade a proteção e segurança dos interesses difusos e coletivos.

Por fim, as garantias constitucionais previstas na Lei Máxima prestam o amparo e tutela para efetivar as normas constitucionais. Cumpre recordar que para o êxito de tal empreendimento, a atuação participativa dos indivíduos e o determinismo político social do Poder Público são indispensáveis.

\section{Considerações finais}

Ante todo o exposto, o Neoconstitucionalismo surgiu na Europa, depois da Segunda Guerra Mundial, na Alemanha e Itália. No Brasil, este novo Constitucionalismo surgiu com a Constituição Federal de 1988 em meio a um cenário de "ressaca" do regime ditatorial.

É escorreito afirmar que com a Carta Magna de 1988, o Constitucionalismo Contemporâneo entra em voga, suscitando a efetivação dos direitos fundamentais e do princípio da dignidade da pessoa humana. Também, assevera-se que no Brasil houve várias promulgações de Constituições ao longo dos anos, não obstante, somente a atual Carta 
Constitucional de 1988 prevê a verossímil aplicação das normas constitucionais à realidade brasileira.

O Neoconstitucionalismo consiste na força imperativa da Constituição, na sua supremacia diante das normas infraconstitucionais, na sua aplicabilidade integral à sociedade, de modo a ensejar vida digna, justa e adequada.

0 instituto Neoconstitucionalista pugna por uma nova visão do Direito, na qual a Constituição não deve ser interpretada somente como um conjunto de normas e regras, mas sim, como um mecanismo capaz de regular qualquer aspecto da vida social e política, primando pelo bem estar social e pela materialização dos valores constitucionais.

Hodiernamente, com a nova tendência constitucional ora defendida, a ciência jurídica tenta se voltar mais para os valores concretos, ao invés de se limitar apenas à aplicação abstrata da lei. Assim, pode-se dizer que o ordenamento jurídico brasileiro caminha rumo à valorização dos axiomas constitucionais, levando-se em consideração que há, todavia, muito a se percorrer pela plena efetivação dos direitos fundamentais e valores éticos, morais constitucionais.

Infelizmente, o Neoconstitucionalismo, na atualidade, possui aplicação incipiente e frágil no Brasil, incapaz de atender a todas as demandas sociais e políticas.

Pode-se salientar que os valores mais importantes da civilização devem ser colocados em prática, pois eles existem, porém, não são efetivados da maneira como deveriam ser.

Em meio à desmoralização do civilismo, ao desrespeito aos princípios constitucionais, faz-se vinculante a presença imediata de instrumentos e procedimentos para a efetivação adequada da Constituição. Dessa forma, deve-se ansiar por medidas práticas eficazes, capazes de assegurarem a igualdade, a solidariedade, a fraternidade, e, sobretudo, capazes de fazerem prevalecer o bem estar social, isso sim condiz com a ciência Neoconstitucionalista.

Este trabalho demonstrou que a Constituição Federal de 1988 é uma ferramenta de concretização dos direitos coletivos, assim como dos direitos humanos, visando à universalização dos direitos e liberdades.

o Neoconstitucionalismo visa o emprego de técnicas que materializem os direitos fundamentais, que constituem, por sua vez, na estrutura básica do Estado e da sociedade. 
Essa ciência neoconstitucionalista pretende abolir todo tipo de leniência e inércia que impedem a real efetivação do direito constitucional.

Destarte, o Neoconstitucionalismo deve propor a integração, a universalização, e a equidade, tendo como premissa basilar a ascensão dos direitos fundamentais, juntamente com o princípio da dignidade humana.

\section{Referências}

ÁVILA, Humberto. "Neoconstitucionalismo": Entre a "Ciência do Direito e o "Direito da Ciência". Revista Eletrônica de Direito do Estado (REDE), Salvador, Instituto Brasileiro de Direito Público, n. 17, janeiro, fevereiro, março. 2009, disponível na Internet: WWW.direitodoestado.com.br/rede.asp.

BARROSO, Luís Roberto. O direito constitucional e a efetividade de suas normas: limites e possibilidades da Constituição Brasileira. 9. Ed. Rio de Janeiro: Renovar, 2009.

BARROSO, Luis Roberto. Neoconstitucionalismo e Constitucionalização do Direito. (0 triunfo Tardio do Direito Constitucional no Brasil). Revista Eletrônica sobre a Reforma do Estado (REFE), Salvador, Instituto Brasileiro de Direito Público, n. 9, Março, Abril, M aio, 2007. Disponível na internet: WWW.direitodoestado.com.br/rere.asp.).

BULOS, Uadi Lammêgo. Direito Constitucional ao alcance de todos. 2 ed. São Paulo: Editora Saraiva, 2010.

CADEM ARTORI, Luiz Henrique Urquhart e DUARTE, Francisco Carlos. Estado de Direito no Contexto do Neo-constitucionalismo e o Papel das Garantias Fundamentais.

Constituição Federal de 1988.

CUNHA, José Ricardo, BORGES, Nadine, BUENO, M ariza do Nascimento Silva Pimenta, LAVIGNE, Rosane M aria Reis, M ARÇAL, Regina Elizabeth Tavares, Direitos Humanos e Poder Judiciário no Brasil, Federalização, Lei Maria da Penha e Juizados Especiais Federais. 1 ed., Rio de Janeiro: Escola de Direito do Rio de Janeiro da Fundação Getúlio Vargas, Centro de Justiça e Sociedade, 2009.

DA SILVA, Denival Francisco e outros. Sistema Punitivo e os 20 anos da Constituição. Os Direitos Fundamentais no M undo Globalizado: 0 Judiciário a Reboque das M udanças Sociais e Políticas. Goiânia, Kelps, 2009.

DINIZ, M aria Helena. Compêndio de Introdução à Ciência do Direito. 18 ed. São Paulo: Editora Saraiva, 2006, p. 43. 
DO VALE, André Rufino. Aspectos do Neoconstitucionalismo. Revista Brasileira de Direito Constitucional-RBDC n. 09, janeiro, junho, 2007.

Instituto Brasileiro de Geografia e Estatística-WWW.ibge.gov.br, acesso em setembro de 2010.

JELLINEK, Georg. Teoria general del Estado, 1981, p. 591.

LEITE, Eduardo de Oliveira. M onografia Jurídica. 7 ed. São Paulo: Editora Revista dos Tribunais, 2006.

LENZA, Pedro. Direito Constitucional Esquematizado. 13 ed. São Paulo: Editora Saraiva 2009.

LOM EU, Leandro Soares. Aspectos do Neoconstitucionalismo.

M ARCONI, M arina de Andrade. M etodologia Científica: para o curso de Direito. 2 ed. São Paulo: Editora Atlas S.A, 2001.

M inistério Público do Estado de Goiás- Plano Estratégico do M PGO 2009-2022, WWW.mpgo.go.gov.br, acesso em 01/04/2011.

M IRANDA, Jorge. Manual de direito constitucional. 4. Ed. Coimbra: Coimbra Editora, p. 8889.

M ORAES, Alexandre de. Direito Constitucional. 16 ed. São Paulo: Atlas, 2004.

NOSETE, José Almagro. Constitución y proceso, 1984, p. 13-15.

PELAYO, M anuel Garcia. Derecho constitucional comparado, 1967, p. 20.

Portal do Conselho Nacional de Justiça- WWW.cnj.jus.br, acesso em setembro 2010.

Releituras, WWW.releituras.com.br, acesso em 01/04/2001.

RESENDE, Vera Lúcia Pereira. Os Direitos Sociais Como Cláusulas Pétreas Na Constituição Federal De 1988. Mestrado em Direito. São Paulo, Osasco: UNIFIEO - CENTRO UNIVERSITÁRIO FIEO, 2006.

ROSSI, Amélia Sampaio. Neoconstitucionalismo e Direitos Fundamentais. Introdução. Constitucionalismo Contemporâneo X Positivismo Jurídico. A realização dos direitos fundamentais sob a perspectiva Neoconstitucionalista. Conclusão.

SARLET, Ingo Wolfgang. A eficácia dos Direitos Fundamentais. Uma teoria geral dos direitos fundamentais na perspectiva constitucional. 10 ed. Porto Alegre: Livraria do Advogado Editora, 2011. 
SCHIER, Paulo Ricardo. Novos desafios da filtragem constitucional no momento do Neoconstitucionalismo. Revista Eletrônica de Direito do Estado, Salvador, Instituto de Direito Público da Bahia, n. 4, outubro, novembro, dezembro, 2005. Disponível na Internet: WWW.direitodoestado.com.br.

STRECK, Lenio Luiz. A revolução copernicana do (neo) constitucionalismo e a (baixa) compreensão do fenômeno no Brasil- uma abordagem à luz da hermenêutica filosófica.

ZAVERUCHA, Jorge e SOARES, Glaucio. STM e fragilidade da democracia. Folha de São Paulo, tendências e debates, 24 de novembro de 2010, acesso em 24/11/2010.

Artigo recebido em:

23 jun. 2011

Artigo aprovado em:

13 nov. 2011 